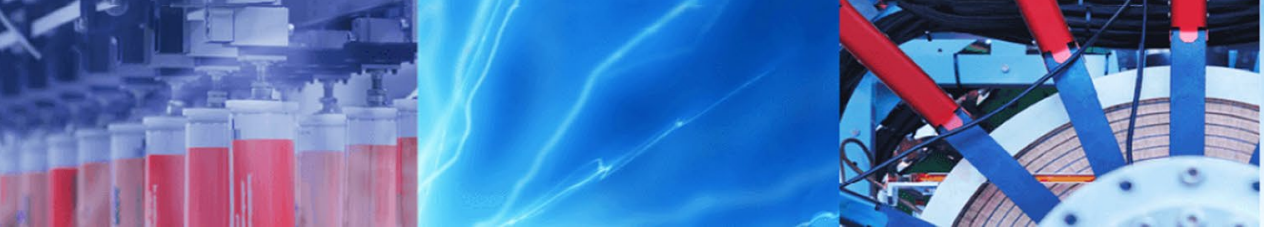

Editorial

\title{
Remote sensing and GIS applications in earth and environmental systems sciences
}

\author{
Helder I. Chaminé ${ }^{1,2}$ (D) Alcides J. S. C. Pereira ${ }^{3} \cdot$ Ana C. Teodoro $^{4} \cdot$ José Teixeira $^{5}$
}

Accepted: 2 November 2021

Published online: 15 November 2021

(c) The Author(s) 2021 OPEN

Remote sensing provides essential data about objects at or near the earth's surface and the atmosphere based on radiation reflected or emitted from objects or areas in multiscale and multitemporal approaches. Remote sensing techniques use satellite and or airborne sensors to collect information about a given object or area. Thus, they depend on their physical, chemical, biological and or geological properties. The measurement and recording of the electromagnetic radiation are made by sensors mounted on a platform (namely, satellite, aerial, unmanned airborne systems) above the earth's surface. The sensors can be mounted from a few hundred meters above the earth's surface (e.g., high-resolution multispectral and hyperspectral imagers, light detection and ranging (LiDAR), and radar systems) to hundreds (or even thousands) of kilometres (e.g., orbital satellites). Remote sensing data collection methods can be passive or active. Passive sensors (e.g., spectral imaging) detect natural radiation emitted or reflected by the observed object or area. Active sensors have their own energy source, which is emitted in the direction of the object (e.g., radar), and the resultant signal reflected back is measured (e.g., [5, 6]).

In this approach, remote sensing provides an impressive amount of geospatial information and data. That offers a cost-effective way in environmental and ground change detection and monitoring. Thus, it is a powerful tool in fundamental and applied sciences, particularly in the environmental, geographical and geoscience fields.

Recent technological advances in Geographic Information System (GIS) techniques and methodologies, combined with the analysis of remotely sensed data, have proven to be powerful tools in fundamental and applied geosciences (e.g., geological mapping, geomorphology, structural geology, hydrogeology, geophysics, geological exploration), applied sciences and engineering (geomatic, geological, geotechnical, mining, civil, environmental), geography and land planning, hydrology and water resources, atmospheric science and meteorology, natural hazards, among others. In addition, GIS methodologies is a forefront approach to support conceptual site models and site investigations mapping encompassing data analysis, visual analytics and support design solutions (e.g., [1, 2, 7-9]).

Geovisualisation is a developing field of computing science with the fundamental approach that displaying visual representations of data assists humans in generating ideas and hypotheses about the data set (e.g., [3, $4,9])$. In the applied sciences, coupling remote sensing and GIS-based mapping are helpful for data visualisation, spatial analysis, and a better understanding of the functioning of the earth, water and environmental systems. Thus, GIS and remote sensing played a crucial role in research and practice, with several applications for

$\triangle$ Helder I. Chaminé, hic@isep.ipp.pt | 'Laboratory of Cartography and Applied Geology (LABCARGA), Department of Geotechnical Engineering, School of Engineering (ISEP), Polytechnic of Porto, Porto, Portugal. ${ }^{2}$ Centre GeoBioTec|UA, Aveiro, Portugal. ${ }^{3}$ Centre for Earth and Space Research (CITEUC), Department of Earth Sciences, Faculty of Sciences and Technology, University of Coimbra, Coimbra, Portugal. ${ }^{4}$ Earth Sciences Institute (ICT) - FCUP Pole, Department of Geosciences, Environment and Land Planning, Faculty of Sciences, University of Porto, Porto, Portugal. ${ }^{5}$ Centre of Studies in Geography and Spatial Planning (CEGOT) - FLUP Pole, Department of Geography, Faculty of Arts, University of Porto, Porto, Portugal.

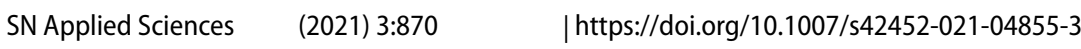


spatial data, geovisualisation and modelling in earth and environmental sciences.

The topical collection (TC) on "Remote Sensing and GIS Applications in Earth and Environmental Systems Sciences" includes 25 selected contributions in remote sensing, geospatial analysis, and GIS-based mapping for the earth and environmental systems. The themed issue highlights key emerging research topics in remote sensing for geomorphology, geosciences, engineering, water resources, urban planning, natural hazards. In addition, the TC includes several model regions that shape the spectrum of the theme, mainly in Asia (India, Bangladesh, Pakistan, Mongolia), the Middle East (Turkey, Iraq, Iran), Africa (Nigeria, Ghana), America (USA, Brazil), and Europe (Portugal). Thus, the TC is of interest to all researchers and practitioners in geomatic engineering, applied geosciences, water management, hydrologic engineering, urban planning and natural hazards.

There is a comprehensive array of applications for remote sensing and GIS-based mapping applications in earth and environmental sciences, as shown in this TC. Articles here address several approaches: (i) a set of papers addressing studies in remote sensing-based mapping on biodiversity, forestry and land cover issues; (ii) several papers are related mainly to GIS mapping and remote sensing techniques for delineating potential groundwater recharge zones, remote sensing and GIS-based analysis for urban sprawl, sustainable groundwater resources management for the evaluation of potential recharge zones using geospatial and Multiple-Criteria Decision-Making (MCDA) techniques, and GIS-based modelling for irrigation water suitability; (iii) a valuable set of papers highlighting a novel technique for developing flood hazard map by using AHP (Analytical Hierarchy Process), case studies underlining depletion of surface water bodies and floodplains using geospatial analysis, and land use/cover mapping change derivated from flood issues; (iv) a set of articles stressing the importance and application of spatial variability analysis and GIS-mapping on soil studies; (v) several case studies related to assessment of public open spaces and landscape quality, integrated remote sensing and fieldbased mapping to delineate glacial landform features, and remote sensing-based evaluation on river morphology evolution; (vi) other papers highlight several applications of remote sensing techniques, such as: coupling a hierarchical clustering and stochastic distance for indirect semi-supervised remote sensing image classification; discussing a geospatial analysis of electricity in an integrated hybrid renewable energy system model; presenting a numerical approach for ionospheric delay estimation of single-frequency NavIC satellite receiver, and showing a study related to the integration of $C$ band
SAR (Synthetic-Aperture Radar) and optical temporal data for identification of paddy fields.

Remote sensing and GIS-based mapping for the earth and environmental systems need to advance towards a comprehensive cartographic reasoning concept founded, among others, in geomatic techniques, fieldwork, georeferenced data using high-precision GPS (Geographical Positioning System) for the fieldwork survey and high-resolution digital imagery acquired by an unmanned aerial vehicle (UAV), earth-based systems conceptualisation and numerical modelling. Last but not least, remote sensing and GIS applications for the earth and environmental systems address a conceptual and practical context for a better understanding of the functioning of the natural systems in climate change framework and support design solutions with natural hazards.

Acknowledgements The guest editors are deeply grateful for the challenge and enthusiastic support of the Managing Editor, Dr. Clifford Chuwah (Earth and Environmental Sciences Section), at all the stages of preparing this topical collection. A word of appreciation also to the full support during the preparation process of topical collection (TC) of the Assistant Editor, Dr. Inna Melnyk, JEO Assistant, Ms. Vidhya Velayudhan, and the Springer production team for their efforts in editing TC. A special thanks to the reviewers for their valuable inputs during the peer-reviewing process to enhance the overall quality of the manuscripts.

\section{Declarations}

Conflict of interest The author(s) declare that they have no competing interests.

Open Access This article is licensed under a Creative Commons Attribution 4.0 International License, which permits use, sharing, adaptation, distribution and reproduction in any medium or format, as long as you give appropriate credit to the original author(s) and the source, provide a link to the Creative Commons licence, and indicate if changes were made. The images or other third party material in this article are included in the article's Creative Commons licence, unless indicated otherwise in a credit line to the material. If material is not included in the article's Creative Commons licence and your intended use is not permitted by statutory regulation or exceeds the permitted use, you will need to obtain permission directly from the copyright holder. To view a copy of this licence, visit http://creativecommons. org/licenses/by/4.0/.

\section{References}

1. Chaminé HI, Teixeira J, Freitas L, Pires A, Silva RS, Pinho T, Monteiro R, Costa AL, Abreu T, Trigo JF, Afonso MJ, Carvalho JM (2016) From engineering geosciences mapping towards sustainable urban planning. Eur Geol J 41:16-25

2. Duarte L, Teodoro AC (2021) GIS Open-source plugins development: a 10-year bibliometric analysis on scientific literature. Geomatics 1:206-245 
3. Dykes J, Maceachren AM, Kraak M-J (2005) Exploring geovisualization. International Cartographic Association Elsevier, Oxford

4. Fisher PF, Dykes JA, Wood JD (1993) Map design and visualisation. Cartogr J 30(2):136-142

5. Lillesand TM, Kiefer RW, Chipman JW (2015) Remote sensing and image interpretation, 7th edn. Wiley, Hoboken

6. Sabins FF Jr, Ellis JM (2020) Remote sensing: principles, interpretation, and applications, 4th edn. Waveland Press Inc., Long Grove

7. Teixeira J, Chaminé HI, Carvalho JM, Pérez-Alberti A, Rocha $F$ (2013) Hydrogeomorphological mapping as a tool in groundwater exploration. J Maps 9(2):263-273
8. Teodoro AC (2016) Optical satellite remote sensing of the coastal zone environment: an overview. In: Marghany M (ed) Environmental applications of remote sensing. IntechOpen, London, pp 165-196. https://doi.org/10.5772/61974

9. Turner AK, Kessler H, van der Meulen MJ (2021) Applied multidimensional geological modeling: informing sustainable human interactions with the shallow subsurface. Wiley, Chichester

Publisher's Note Springer Nature remains neutral with regard to jurisdictional claims in published maps and institutional affiliations. 